\title{
RESEÑAS
}




\section{EN LA LUCHA POR LA HISTORIA DE LA CULTURA*}

Víctor Manuel Prieto

El primer tomo del trabajo de la doctora Müller ofrece una visión histórica de los intentos por crear un sistema de formación del magisterio en Colombia durante el siglo XX. A partir de una cuidadosa revisión de las disposiciones legislativas confronta las políticas educativas oficiales con las condiciones sociales del país, y las compara con la situación europea que las orienté y sirvió de base. Para el análisis de los fundamentos y realizaciones de la legislación educativa la autora tiene en cuenta el contexto social del país, así como las posturas ideológicas de las personas que promovieron y atacaron las reformas que se proponían.

Al medir la eficacia de las políticas impulsadas por el Estado para establecer un sistema de formación de docentes, se documenta en las constituciones políticas y las leyes, decretos y resoluciones que las desarrollaron. Con ello busca esclarecer su contenido ideológico y la forma como se materializaron esas disposiciones en las instituciones educativas creadas para la formación del magisterio colombiano. Buscando explicar las diferencias entre el modelo que se buscaba imitar, y apoyándose en fuentes secundarias, describe el contexto político y cultural de Europa, especialmente el alemán y lo compara con el medio social colombiano.

Inicialmente aborda el papel de la segunda misión pedagógica alemana en la organización de las instituciones formadoras de docentes que se crearon durante la primera mitad del siglo XX en el país. Para establecer la orientación de la misión en Colombia, parte de la reseña de la concepción ideológica de la Constitución de Weimar, de tendencia social-liberal. Ese espíritu se expresó en el proyecto de ley que presentó la misión al gobierno nacional, pero debido a la oposición del clero y de miembros del partido conservador, no fue aprobado por el parlamento. Sin embargo, señala como la propuesta fue retomada más adelante por el gobierno de la revolución en marcha de López Pumarejo.

Para explicar las objeciones que se le hicieron al proyecto de ley presentado por la misión, centra el análisis en la visión del dirigente conservador Antonio José Uribe, considerado una autoridad en asuntos educativos durante las tres primeras décadas de este siglo. A partir de una cuidadosa revisión de la legislación educativa. La doctora Müller indica la semejanza de algunas de las disposiciones de la reforma emprendida por los radicales en 1870 con las de la ley orgánica de 1903 y el decreto 491 de 1904, disposiciones que fueron producto de las labores de Antonio José Uribe, cuando se desempeñé como Ministro de Instrucción Pública.

En su trabajo también señala algunos de los puntos más avanzados de la reforma propuesta por la Segunda Misión Pedagógica Alemana, como la responsabilidad del Estado en el manejo y control de la educación, la ordenación de un escalafón docente para dignificar el oficio del profesor y la preocupación por ofrecer a la mujer una educación que la pusiera en igualdad de condiciones con el varón, aspectos que no fueron mencionados por Antonio José Uribe en la polémica que emprendió para atacar el proyecto.

\footnotetext{
"MULLER, Ingrid. La lucha por la cultura (Bogotá: Universidad Pedagógica Nacional, 1992), tomo I. 
Plantea que la puesta en marcha del Instituto Pedagógico Nacional para Señoritas, donde se aplicaron métodos de enseñanza modernos, fue el primer resultado de las labores de la Segunda Misión Pedagógica Alemana. Y de acuerdo con los planteamientos de la doctora Müller, allí se logró ofrecer por primera vez en el país una educación avanzada a la mujer. Para mostrar la eficacia del plantel analiza su funcionamiento entre 1927 y 1935, tiempo en que estuvo bajo la dirección de la doctora Francisca Radke, quien contó con la colaboración de un equipo de docentes alemanes.

Examina la organización del colegio, su escuela anexa y la programación de los cursos de perfeccionamiento de maestros, aspectos que son tratados para explicar el liderazgo que tuvo la institución bajo la dirección de la pedagoga alemana. Ana-liza además la reorientación del Instituto en 1955 cuando, bajo la dirección de Francisca Radke, se convirtió en la Universidad Pedagógica Femenina.

Y por último trata la formación impartida en la Escuela Normal Superior que, como iniciativa del gobierno de López Pumarejo, buscaba unificar las instituciones formadoras de docentes del país. Con la colaboración de destacados intelectuales europeos, especialmente españoles, franceses y alemanes que huían del nazismo, y a partir de una cuidadosa selección de los estudiantes, la Escuela Normal orientó su formación hacia la preparación de docentes investigadores. Muestra como el plan de estudios de la institución hacía énfasis en dotar a los estudiantes del conocimiento de los métodos de trabajo de las ciencias puras, mecanismo con el cual logró formar docentes investigadores con aptitud científica.

Dentro del trabajo de la doctora Müller el coinvestigador Daniel Ceballos hace una reseña del Instituto de Filosofía y Letras de la Universidad Nacional. En él describe el espíritu académico de la institución, su autor argumenta que gracias a que el Instituto contaba con la autonomía académica propia de la Universidad Nacional, y que a pesar de las presiones de los gobiernos conservadores, allí se logró infundir un espíritu de libertad de pensamiento en los estudiantes que se formaron luego de su creación en 1945 bajo la rectoría de Gerardo Molina.

Para penetrar en la orientación que se le dio a las instituciones creadas para organizar un sistema de formación del magisterio en el país, la doctora Müller hace el análisis de cada una de ellas. Allí muestra el marco legislativo que les dio origen, las personas que estuvieron vinculadas a los proyectos, las concepciones pedagógicas que se expresaban en sus planes de estudio, los mecanismos empleados para seleccionar a los estudiantes así como sus realizaciones. Explica además, como ninguna de esas instituciones logró formar una generación de docentes que estuviera en condiciones de influir en la transformación del sistema educativo colombiano.

A partir del estudio del funcionamiento de estas instituciones, hace una comparación de la situación de los establecimientos encargados de formar los docentes europeos, ya que estos sirvieron de modelo en Colombia. Muestra también cómo las condiciones sociopolíticas del país, principalmente la influencia que ejercía el clero en la educación, impidieron que un sistema de formación de docentes con una orientación avanzada tuviera continuidad.

A pesar de que su trabajo revela rigor en la investigación, la doctora Müller deja a un lado el análisis otros intentos del Estado por crear un sistema de formación de docentes. Tentativas como las realizadas por los hermanos cristianos durante la hegemonía conservadora, tan sólo se mencionan. Esa comunidad, según lo afirma Aline Helg, se 
caracterizó por la aplicación de métodos pedagógicos avanzados, especialmente cuando estuvo a cargo de la Normal Central de Institutores. Esta omisión deja un vacío en el análisis histórico de los intentos de crear un sistema de formación de docentes en el país.

Sin embargo, este primer tomo de La lucha por la Cultura representa un importante aporte para la historia del magisterio en nuestro país. A diferencia de otros trabajos que se han realizado sobre el mismo tema, en esta obra el asunto es tratado con rigor histórico. Apoyándose en una amplia documentación, tiene en cuenta la situación internacional y el contexto político-cultural de la sociedad colombiana y la exposición de sus planteamientos es realizada en un lenguaje claro. 